\title{
A cross-sectional study of socioeconomic status and cardiovascular disease risk among participants in the Prospective Urban Rural Epidemiological (PURE) Study
}

\author{
B A Egbujie, MBBS, MPH; E U Igumbor, MPH, PhD; T Puoane, MPH, DrPH \\ School of Public Health, University of the Western Cape, Bellville, Cape Town, South Africa
}

Corresponding author: B A Egbujie (greatdabon@yahoo.com)

Background. Cardiovascular diseases (CVDs) are a challenge to populations and health systems worldwide. It is projected that by 2020 about a third of all deaths globally will be caused by CVDs, and that they will become the single leading cause of death by 2030. Empirical evidence suggests that there is socioeconomic patterning in the distribution and prevalence of risk factors for CVD, but the exact nature of this relationship in South Africa remains unclear.

Objective. To examine the association between socioeconomic status (SES) and risk factors for CVD in a cohort of adult South Africans living in rural and urban communities.

Method. This was a cross-sectional analytical study of baseline data on a population-based cohort of 1976 SA men and women aged 35 - 70 years who were part of the Cape Town arm of the Prospective Urban and Rural Epidemiology (PURE) Study.

Results. We found a complex association between SES and CVD risk factors, its pattern differing between urban and rural participants. Marital status showed the most consistent association with CVD risk in both groups: widowed participants living in urban communities were more likely to be hypertensive as well as diabetic, while single participants in both locations were more likely to use alcohol and tobacco products. Level of education was the only SES variable that had no significant association with any CVD risk factor in either study group. All measured SES variables were significantly different between urban and rural participants $(p<0.05)$, with diabetes, obesity and alcohol use significantly more prevalent in urban than in rural participants $(p<0.05)$ while hypertension and tobacco use were not $(p \geq 0.05)$.

Conclusions. In this cohort of South Africans, there were significant associations between SES and CVD risk, with marked differences in these associations between rural and urban locations. These findings highlight the need to consider SES and area of residence when designing interventions for CVD prevention and control.

S Afr Med J 2016;106(9):900-906. DOI:10.7196/SAMJ.2016.v106i9.10456

Non-communicable diseases (NCDs), including cardiovascular disease (CVD), are the leading cause of death globally, accounting for about $68 \%$ of all deaths in $2012 .{ }^{[1]}$ CVD alone accounted for $29.2 \%$ (16.7 million) of all deaths globally in 2003 , rising to $30 \%$ (17.5 million) in 2005 , and was expected to contribute to 20 million deaths by $2015{ }^{[2]}$ It is estimated that 23.6 million people will die from CVD alone by the year 2030, which will make CVD the leading single cause of death worldwide. ${ }^{[3]}$

Currently $>80 \%$ of CVD deaths occur in low- and middleincome countries (LMICs). ${ }^{[1]}$ In South Africa (SA), national mortality statistics showed that CVD, diabetes, respiratory diseases and cancer were responsible for $12 \%$ of the overall disease burden ${ }^{[4,5]}$ and an estimated 195 people per day died of CVD between 1997 and 2004. ${ }^{[6]}$

An increasing prevalence of CVD risk factors is associated with rapid urbanisation across the globe, particularly in SA and other LMICs. ${ }^{[7]}$ In its 2006 report on migration and urbanisation (as cited in Puoane et al. $\left.{ }^{[7]}\right)$, Statistics South Africa stated that the proportion of black Africans living in urban areas in SA increased from $43.3 \%$ in 1996 to $47.5 \%$ in $2001,{ }^{[7]}$ and the lifestyle of these individuals has also changed during this period. Changing lifestyle (dietary changes and inactivity) is associated with urbanisation, and it has been suggested that this plays a role in the development of CVDs. ${ }^{[7]}$

Socioeconomic patterning in the distribution and prevalence of risk factors for CVD has also been suggested. ${ }^{[8]}$ It has been reported that this patterning is negative in developed nations, where CVD affects more people of lower socioeconomic status (SES), and positive in developing nations, where it affects more people of higher SES. ${ }^{[9,10]}$
There is equally the existence of both positive and negative associations between SES and CVD risk factors, even within a country, ${ }^{[10]}$ reflecting the complex nature of the links between these factors. This phenomenon is attributed in part to differences in level of development between different regions in each country, and highlights the influence social disadvantage may have on CVD risk factors. It is known that people's experience of health or disease flows directly from their social resources and circumstances, ${ }^{[11]}$ so any disease that has SES patterning will be of significant impact in SA, which has an income (wealth) distribution that is one of the most unequal in the world, as reflected by a Gini coefficient of $0.63 .^{[12]}$

\section{Objective}

Literature on the association between SES and CVD risk factors in SA is sparse. We sought to determine the association between socioeconomic factors and risk of CVD in South Africans in an urban and a rural population.

\section{Methods}

\section{Study design}

We analysed data from the Cape Town arm of the PURE Study, a longitudinal cohort study of 1976 SA men and women aged 35 - 70 years, which started in 2009 and aims to investigate the relative contribution of societal influences on individual lifestyle choices and risk factors for NCDs. This arm of the study has two cohorts, a rural cohort of participants recruited from Mount Frere, Eastern Cape Province, and an urban cohort recruited from Langa, Cape Town. 


\section{Study setting}

Mount Frere is located in Alfred Nzo district in the Eastern Cape, which is largely rural and mainly inhabited by isiXhosa-speaking black South Africans. Langa township is located in the Cape Town metropolitan district in the Western Cape Province, is urban and is also mainly inhabited by isiXhosa-speaking black South Africans.

\section{Sampling strategy}

The two communities were purposefully selected for the study because the research team had established research interactions with them, which made long-term follow-up of individuals in the community feasible.

In the urban community, individuals were recruited to join the cohort using a multistage sampling approach. First, households were grouped into three development areas that mirrored the SES of the residents. Then a street map obtained from the City of Cape Town was used to randomly select streets in each of the three areas. Once a street was selected, a systematic sample of every second house was approached for possible inclusion in the study. Eligible households for the study were those with at least one member aged 35 - 70 years.

In the rural community, streets and households are informal, irregular and unnamed and houses are unnumbered, making it impossible to follow the same sampling approach. We therefore used a single-staged cluster sampling approach as recommended by the World Health Organization for Expanded Programme on Immunization surveys. ${ }^{[13]}$ We defined a cluster as a group of adjacent households which served as the primary sampling unit and roughly aligned geographically with administrative boundaries of clan heads. We randomly selected household clusters, undertook a listing procedure of all dwellings/households, and included all households with any individual aged $35-75$ years.

\section{Variables}

For the purpose of this study, four self-reported socioeconomic factors were assessed: level of education, employment status, income and marital status. Education variables were recorded as one of four categories from no schooling (category 1, 0 years) to primary school (category 2, $1-8$ years), secondary school (category 3, 9 - 12 years) and post-secondary school (category $4,>12$ years). Income group was graded according to total amount earned/accruing to an individual's household in a month into low- ( $\leq$ ZAR900), medium- (ZAR901 $1080)$ and high-income groups (>ZAR1 080). Marital status was recorded as single, married/cohabiting, divorced/separated and widow(er). Five major CVD risk factors were the focus of the study, namely obesity, tobacco use, hypertension, diabetes mellitus and alcohol consumption. Other risk factors such as physical inactivity and lipid levels have not been included in the analysis because data were not available at the time of analysis.

\section{Statistical analysis}

Data analysis was performed using SPSS software, version 17 for Windows (Microsoft, USA). Univariate analysis was conducted on the socioeconomic and CVD risk factor variables and was performed separately for rural and urban study participants. Multivariate age- and sex-adjusted analysis was conducted to establish the individual and collective relationship between the independent variables (socioeconomic factors) and the dependent variables (CVD risk factors) for each of the populations. The $\chi^{2}$ test was applied to test for differences in data obtained between the rural and urban populations (for nominal data). In all analyses, statistical significance was set at $p<0.05$
The body mass index was categorised as underweight $\left(<18.5 \mathrm{~kg} / \mathrm{m}^{2}\right)$, normal $\left(18.5-24.9 \mathrm{~kg} / \mathrm{m}^{2}\right)$, overweight $\left(25.0-29.9 \mathrm{~kg} / \mathrm{m}^{2}\right)$ and obese $\left(>30.0 \mathrm{~kg} / \mathrm{m}^{2}\right)$.

Hypertension was taken as a systolic blood pressure of $\geq 140 \mathrm{mmHg}$ and/or a diastolic blood pressure of $\geq 90 \mathrm{mmHg}$ and/or a self-reported diagnosis of hypertension and/or use of antihypertensive drugs regardless of blood pressure reading during physical examination. Blood pressure was taken as the average of two readings after the participants had rested for 15 minutes. The second reading was taken at least 30 minutes later if the first was abnormal.

Diabetes was defined as a self-reported diagnosis of diabetes and/ or use of medication for diabetes; undetected diabetes was therefore not included. Alcohol and tobacco use were categorised into three groups as current, former and never users.

\section{Results}

\section{Study population and demographic profile}

The PURE study recruited 1976 individuals, of whom 1942 met the study criteria and were included in this analysis. Of these, 395 (71.8\%) were females and $547(28.2 \%)$ males; 1040 participants (53.6\%) lived in the urban location, while 902 (46.4\%) were rural residents. The mean age of the participants was 49.83 years (standard deviation (SD) 10.08), the mean ages of urban (49.33 years, SD 10.39) and rural participants (50.11 years, SD 10.51) showing no statistically significant difference ( $p=0.135$ ). There was also no statistically significant difference between the mean ages of male and female participants $(p=0.343)$.

\section{Socioeconomic characteristics of study participants}

Table 1 shows the sociodemographic characteristics of study participants according to location of residence. The median monthly household income for urban participants was ZAR1 500 (interquartile range (IQR) 1010 - 3000 ), and was significantly higher than the income of participants living in rural communities (median ZAR1 010, IQR 700 - 1250$)(p<0.001)$.

\section{Prevalence of CVD risk factors}

Overall

The prevalence of hypertension was 72.8\% (954/1 311 participants with data on hypertension) among both rural and urban participants, using the set diagnostic criteria; 492/1 311 (37.5\%) were known hypertensives and were already on medication with varying levels of control, while the rest were found to have raised blood pressure for the first time during the study. Of the participants with data on weight, $70.5 \%$ (786/1 115) were at least overweight, $48.5 \%$ (541/1 115) were obese and $2.9 \%(32 / 1115)$ were underweight. The prevalence of diabetes was $10.0 \%$ (188/1 882) among both urban and rural participants. Of the participants, $21.0 \%(408 / 1857)$ currently used a tobacco product and $18.5 \%$ (359/1 857) currently consumed alcohol.

\section{Prevalence according to location}

The prevalence of hypertension was $74.0 \%$ (421/569) among urban and $71.8 \%$ (533/742) among rural participants, while that of diabetes was $11.6 \%$ (114/984) among urban and 8.2\% (74/898) among rural participants; $57.7 \%(246 / 426)$ of urban participants compared with $42.8 \%(295 / 689)$ of rural participants were found to be obese. The prevalence of alcohol use was 24.1\% (235/977) among urban compared with $13.8 \%$ (124/900) among rural participants.

Fig. 1 shows a comparison of the prevalence of CVD risk factors between the urban and rural participants. All risk factors with the exception of tobacco use were more prevalent among urban participants, with diabetes, obesity and alcohol use showing statistically significant differences. 
Table 1. Sociodemographic characteristics of the study participants ( $N=1942)$ according to area of residence ${ }^{\star}$

\begin{tabular}{|c|c|c|c|}
\hline & Urban & Rural & $\chi^{2}$ (Pearson), $p$-value \\
\hline Age (years), mean (SD) & $49.33(10.39)$ & $50.11(10.51)$ & $0.135^{\dagger}$ \\
\hline Sex, $n(\%)$ & & & $10.52,0.001$ \\
\hline Female & $715 / 1040(68.8)$ & $680 / 902(75.4)$ & \\
\hline Male & $325 / 1040(31.3)$ & $222 / 902(24.6)$ & \\
\hline Education, $n(\%)$ & & & $148.89,0.000$ \\
\hline None & $21 / 1007(2.1)$ & $34 / 897(3.7)$ & \\
\hline Primary & 208/1 007 (20.7) & $405 / 897(45.2)$ & \\
\hline Secondary & $697 / 1007(69.2)$ & $429 / 897(47.8)$ & \\
\hline Post-secondary & $81 / 1007(8.0)$ & $29 / 897(3.2)$ & \\
\hline Marital status, $n(\%)$ & & & $88.68,0.000$ \\
\hline Single & $484 / 1028(47.1)$ & $257 / 895(28.7)$ & \\
\hline Married/cohabiting & $386 / 1028(37.5)$ & $424 / 895(47.4)$ & \\
\hline Widow(er) & $89 / 1028(8.7)$ & $165 / 895(18.4)$ & \\
\hline Separated & $69 / 1028(6.7)$ & $49 / 895(41.5)$ & \\
\hline Employment status, $n$ (\%) & & & $10.73,0.001$ \\
\hline Employed & $259 / 942(27.5)$ & $144 / 724(19.9)$ & \\
\hline Unemployed & $683 / 942(72.5)$ & $580 / 724(80.1)$ & \\
\hline Income/month (ZAR) & & & $124.73,0.000^{\dagger}$ \\
\hline Mean (SD) & $2636(3108)$ & $1352(1423)$ & \\
\hline Median (IQR) & $1500(1990)$ & $1010(550)$ & \\
\hline Income group, $n(\%)^{\ddagger}$ & & & $167.43,0.000$ \\
\hline Lowest & $108 / 692(15.6)$ & $264 / 754(35.0)$ & \\
\hline Middle & $313 / 692(45.2)$ & $402 / 754(53.3)$ & \\
\hline Highest & $271 / 692(39.2)$ & $88 / 754(11.7)$ & \\
\hline \multicolumn{4}{|c|}{ *Information was missing for some variables, so denominators vary. } \\
\hline${ }^{\dagger}$ Statistics and significance calcula & sing independent-sampl & it comparing means. & \\
\hline
\end{tabular}

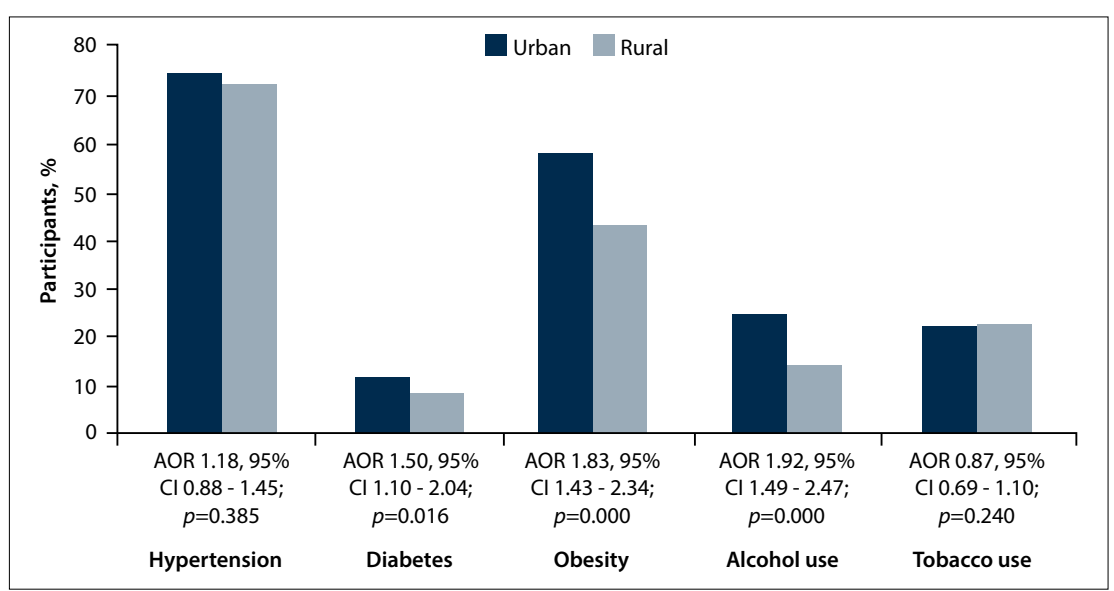

Fig. 1. Age- and sex-adjusted odds ratio (AOR) and 95\% confidence interval (CI) prevalence of CVD risk factors between urban and rural participants.

Prevalence according to age and gender While the prevalence of all CVD risk factors was not affected by age, all risk factors except obesity were associated with gender (Table 2). Female participants had a significantly higher prevalence of hypertension $(75.5 \%, 764 / 1012)$ than males $(63.5 \%, 190 / 299)(p<0.001)$, and $77.5 \%$ (335/432) of female participants in the urban location were found to be hypertensive compared with $74.0 \%(429 / 580)$ of female participants in the rural location. Females also had a higher prevalence of diabetes $(11.0 \%, 150 / 1365)$ than males $(7.4 \%, 38 / 517)$ $(p<0.05)$. Further analysis showed that the prevalence of diabetes did not differ between males and females in the urban location $(12.5 \%$ v. $9.4 \%$; $p>0.05)$, but differed slightly between female and male rural participants $(9.4 \%$ v. $4.5 \% ; p<0.05)$. Tobacco and alcohol use were significantly more prevalent among male participants than among females $(43.1 \%$ v. $14.0 \%$; $p<0.05)$.

\section{Distribution of CVD risk factors according to SES variables}

Table 2 shows the distribution of CVD risk factors according to SES variables. Hypertension had a significant association with participants' marital status, income group and employment status. Diabetes had no significant association with any of the SES variables. Tobacco use had a significant association with marital and employment status, while alcohol use had a significant association with marital status and income group. Surprisingly, education was not found to be associated with any CVD risk factors.

Tables 3 and 4 show the results of multivariate analysis using logistic regression adjusting for age and sex in the urban and rural locations, respectively. The distribution of CVD risk factors according to SES in both the urban and the rural populations showed no consistent pattern; however, the results showed very few differences in associations between the two locations. Single and unemployed participants were more likely to use tobacco and alcohol, while widowed female and high-income participants were more likely to have hypertension or diabetes. Marital status maintained a consistent association with all the CVD risk factors, while income and employment status only retained association with two of the risk factors. Being a widow(er) was the most likely predictor of hypertension in urban locations, with an adjusted odds ratio (OR) of 6.34 (95\% confidence interval (CI) 1.86 - 21.61).

Table 5 shows the differences in SES variables between urban and rural participants by gender disaggregation. Female respondents had significantly lower SES compared with males, and females in the rural community had lower SES compared with females in the urban group.

\section{Discussion}

We sought to determine the association between SES and CVD risk factors in a cohort of South Africans in an urban and a rural population. Our study demonstrated differences and complexities in the patterns of 


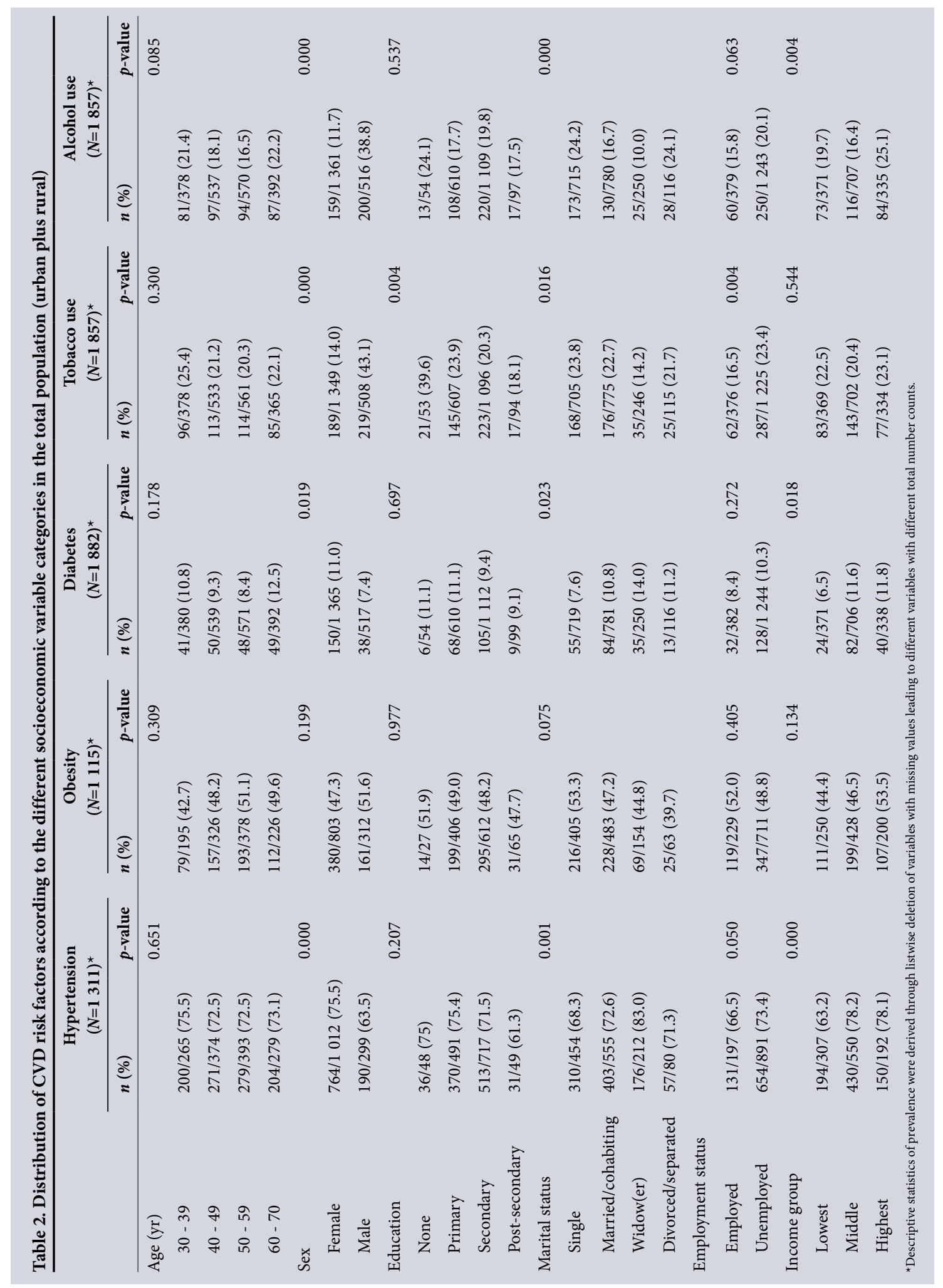

associations between SES and CVD risk factors. It showed that the SES of urban participants was significantly better than that of rural participants and that three of the five selected CVD risk factors were more prevalent in urban participants.

We found that being a widow or widower was a more likely predictor of both hypertension and diabetes for urban than for rural participants, with being male a more likely predictor of alcohol and tobacco use in both the urban and the rural groups. Being a widow or widower therefore appears to be protective against both alcohol and tobacco use for urban participants. The mechanisms for increased susceptibility of widowed persons to CVD risk have been studied, and there is support for our observation that people who have experienced marital loss have a significantly higher prevalence of CVD risk factors than those who are or have never been married. ${ }^{[14]}$ Wilcox et al. ${ }^{[15]}$ reported significant association between marital status and hypertension. 
Table 3. Multivariable logistic regression analysis showing ORs and CIs of CVD risk by SES gradient for urban participants

\begin{tabular}{|c|c|c|c|c|c|c|c|c|c|c|}
\hline & \multicolumn{2}{|c|}{ Diabetes } & \multicolumn{2}{|c|}{ Hypertension } & \multicolumn{2}{|c|}{ Tobacco use } & \multicolumn{2}{|c|}{ Obesity } & \multicolumn{2}{|c|}{ Alcohol use } \\
\hline & OR & $95 \%$ CI & OR & $95 \% \mathrm{CI}$ & OR & $95 \%$ CI & OR & $95 \% \mathrm{CI}$ & OR & $95 \% \mathrm{CI}$ \\
\hline Age & 1.026 & $1.000-1.053$ & 1.01 & $0.985-1.036$ & 0.991 & $0.97-1.012$ & 1.018 & $0.99-1.047$ & 0.989 & $0.97-1.008$ \\
\hline \multicolumn{11}{|l|}{ Sex } \\
\hline Male & 1 & & 1 & & 1 & & 1 & & 1 & \\
\hline Female & 0.996 & $0.557-1.781$ & 1.537 & $0.874-2.703$ & 0.175 & $0.112-0.276$ & 1.116 & $0.635-1.961$ & 0.294 & $0.194-0.444$ \\
\hline \multicolumn{11}{|l|}{ Education } \\
\hline None & 1 & & 1 & & 1 & & & & 1 & \\
\hline Primary & 2.258 & $0.256-19.925$ & 2.071 & $0.310-13.828$ & 0.492 & $0.076-3.180$ & 1.994 & $0.554-7.181$ & 0.753 & $0.132-4.293$ \\
\hline Secondary & 1.004 & $0.115-8.733$ & 1.816 & $0.283-11.652$ & 0.983 & $0.159-6.094$ & 1.007 & $0.44-2.305$ & 1.108 & $0.201-6.116$ \\
\hline Post-secondary & 0.591 & $0.051-6.879$ & 1.403 & $0.170-2.150$ & 0.562 & $0.076-4.153$ & 1.719 & $0.813-3.635$ & 0.821 & $0.129-5.212$ \\
\hline \multicolumn{11}{|l|}{ Marital status } \\
\hline Single & 1 & & 1 & & 1 & & 1 & & 1 & \\
\hline Married/cohabiting & 1.348 & $0.741-2.452$ & 1.930 & $1.129-3.299$ & 0.664 & $0.417-1.058$ & 1.063 & $0.595-1.896$ & 0.714 & $0.465-1.097$ \\
\hline Widow(er) & 2.583 & $1.181-5.650$ & 6.340 & $1.860-21.607$ & 0.448 & $0.177-1.137$ & 0.457 & $0.185-1.133$ & 0.397 & $0.169-0.934$ \\
\hline Divorced/separated & 1.557 & $0.612-3.962$ & 2.562 & $0.811-8.089$ & 0.356 & $0.142-0.894$ & 0.411 & $0.155-1.088$ & 0.733 & $0.352-.526$ \\
\hline \multicolumn{11}{|l|}{ Employment status } \\
\hline Employed & 1 & & 1 & & 1 & & 1 & & 1 & \\
\hline Unemployed & 1.138 & $0.611-2.119$ & 1.206 & $0.676-2.150$ & 2.022 & $1.229-3.325$ & 1.612 & $0.913-2.849$ & 1.785 & $1.137-2.802$ \\
\hline \multicolumn{11}{|l|}{ Income group } \\
\hline Lowest & 1 & & 1 & & 1 & & 1 & & 1 & \\
\hline Middle & 1.700 & $0.750-3.853$ & 2.444 & $1.339-4.460$ & 1.187 & $0.651-2.163$ & 1.895 & $0.875-4.101$ & 1.035 & $0.598-1.790$ \\
\hline Highest & 1.855 & $0.789-4.360$ & 2.479 & $1.268-4.848$ & 1.060 & $0.565-1.989$ & 1.621 & $0.733-3.586$ & 1.194 & $0.676-2.109$ \\
\hline
\end{tabular}

In contrast to the above, being a widow(er) was not significantly associated with hypertension, obesity, or alcohol or tobacco use among rural participants. The influence of other risk factors such as level of physical activity, diet and the presence of supportive social resources in the community could potentially play a role in this differential disease association for rural participants. There are contrasting findings and opinions on differences between levels of physical activity in urban and rural dwellers. Kruger et al. ${ }^{[16]}$ reported that deep rural residents in SA are more likely to be physically inactive than urban residents. In contrast, Steyn et al. ${ }^{[17]}$ were of the opinion that rural residents are more likely to be habitually active than urban residents for reasons that included non-availability of automotive transport in rural settings, contending that fewer urban dwellers need to walk long distances in their activities of daily living. Steyn et al. ${ }^{[17]}$ also noted that dietary intake patterns differ significantly between rural and urban residents, with the former having diets low in fat but high in vegetables and carbohydrates. A combination of a healthier diet and more regular physical activity (both protective) may explain why we found no association between being a widowed rural participant and hypertension and diabetes. It may also explain why all the CVD risk factors were more prevalent in the urban area, as stated above. Neither physical activity nor diet was included in the analysis, so there is the potential for both being confounding factors in our findings.

While urban participants were more likely to be single compared with rural participants, rural participants were more likely to be married or widowed. This seems to suggest that in rural areas people tend to get and stay married for cultural reasons, while in urban locations a larger percentage may choose to remain single or be separated or divorced ${ }^{[18]}$ Differences in marital status in our context are significant, as our study has shown that widowed and single participants face different CVD risk.

Our data indicate that earning a higher income was associated with hypertension in the urban group, while other CVD risk factors (diabetes, obesity) showed no significant association with income. This contrasts with Peer et al'. ${ }^{[19]}$ report of a significant higher prevalence of CVD risk factors (obesity, diabetes, hypercholesterolaemia) among the least poor (higher income) compared with the poorest living in an urban location in SA. The difference between the findings could have resulted from the methods used in describing and categorising individuals into several wealth classes. Peer et al. ${ }^{[19]}$ used pooled data from assets of each individual, while we used the total household income.

Alcohol and tobacco use were found to have similar associations with SES, especially in the urban community, where males and single and unemployed participants were more likely to use both. The pattern of association found may suggest more use of these substances among people of lower SES. Alcohol consumption and tobacco use were both higher in the urban population. The prevalence of alcohol use found in the current study $(15.5 \%$ overall) is lower than that reported in the South Africa Demographic and Health Survey ${ }^{[20]}$ (SADHS 2003) for the black population group (23.2\%). This difference may be explained by the fact that our study cohort had a larger proportion of females, who are reported to have a lower rate of alcohol use than males. There is the possibility of underreporting of alcohol and tobacco use by our study participants. In our study, $38.8 \%$ and $11.7 \%$ of males and females, respectively, reported current alcohol use. This is comparable to the SADHS 2003 findings that $35.2 \%$ and $11.4 \%$ of black males and females, respectively, were current 
Table 4. Multivariable logistic regression analysis showing ORs and CIs of CVD risk by SES gradient for rural participants

\begin{tabular}{|c|c|c|c|c|c|c|c|c|c|c|}
\hline & \multicolumn{2}{|c|}{ Diabetes } & \multicolumn{2}{|c|}{ Hypertension } & \multicolumn{2}{|c|}{ Tobacco use } & \multicolumn{2}{|r|}{ Obesity } & \multicolumn{2}{|c|}{ Alcohol use } \\
\hline & OR & $95 \%$ CI & OR & $95 \% \mathrm{CI}$ & OR & $95 \% \mathrm{CI}$ & OR & $95 \% \mathrm{CI}$ & OR & $95 \% \mathrm{CI}$ \\
\hline Age & 0.996 & $0.967-1.026$ & 0.986 & $0.966-1.005$ & 0.987 & $0.965-1.009$ & 1.002 & $0.983-1.021$ & 0.983 & $0.956-1.011$ \\
\hline \multicolumn{11}{|l|}{ Sex } \\
\hline Male & 1 & & 1 & & 1 & & 1 & & 1 & \\
\hline Female & 3.210 & $1.082-9.517$ & 2.079 & $1.236-3.496$ & 0.161 & $0.099-0.261$ & 0.944 & $0.592-1.505$ & 0.053 & $0.028-0.102$ \\
\hline \multicolumn{11}{|l|}{ Education } \\
\hline None & 1 & & 1 & & 1 & & 1 & & 1 & \\
\hline Primary & 0.721 & $0.148-3.526$ & 0.559 & $0.174-1.795$ & 0.473 & $0.163-1.374$ & 0.367 & $0.091-1.484$ & 0.739 & $0.205-0.267$ \\
\hline Secondary & 0.581 & $0.117-2.894$ & 0.433 & $0.135-1.389$ & 0.254 & $0.086-0.749$ & 0.249 & $0.061-1.009$ & 0.533 & $0.145-1.957$ \\
\hline Post-secondary & 1.968 & $0.268-14.445$ & 0.455 & $0.093-2.218$ & 0.587 & $0.129-2.676$ & 0.203 & $0.038-1.094$ & 0.560 & $0.070-4.493$ \\
\hline \multicolumn{11}{|l|}{ Marital status } \\
\hline Single & 1 & & 1 & & 1 & & 1 & & 1 & \\
\hline Married/cohabiting & 2.112 & $0.873-5.111$ & 1.130 & $0.689-1.855$ & 1.227 & $0.717-2.099$ & 0.899 & $0.574-1.410$ & 0.793 & $0.406-1.548$ \\
\hline Widow(er) & 2.946 & $1.071-8.101$ & 1.198 & $0.600-2.391$ & 0.540 & $0.223-1.310$ & 0.695 & $0.370-1.303$ & 0.482 & $0.124-1.877$ \\
\hline Divorced/separated & 1.441 & $0.278-7.482$ & 0.770 & $0.325-1.828$ & 1.854 & $0.731-4.700$ & 0.646 & $0.240-1.742$ & 1.826 & $0.565-5.906$ \\
\hline \multicolumn{11}{|l|}{ Employment status } \\
\hline Employed & 1 & & 1 & & 1 & & 1 & & 1 & \\
\hline Unemployed & 1.448 & $0.552-14.445$ & 1.981 & $1.133-3.461$ & 1.369 & $0.729-2.572$ & 0.734 & $0.444-1.214$ & 1.115 & $0.516-2.410$ \\
\hline \multicolumn{11}{|l|}{ Income group } \\
\hline Lowest & 1 & & 1 & & 1 & & 1 & & 1 & \\
\hline Middle & 1.464 & $0.694-3.086$ & 1.554 & $0.996-2.422$ & 0.683 & $0.412-1.130$ & 0.881 & $0.578-1.345$ & 0.480 & $0.252-0.915$ \\
\hline Highest & 2.180 & $0.776-6.124$ & 2.432 & $1.053-5.621$ & 0.686 & $0.317-1.486$ & 1.006 & $0.528-1.917$ & 0.340 & $0.123-0.942$ \\
\hline
\end{tabular}

Table 5. Differences in socioeconomic variables between urban and rural participants according to gender

\begin{tabular}{|c|c|c|c|c|c|c|}
\hline & \multicolumn{3}{|c|}{ Males } & \multicolumn{3}{|c|}{ Females } \\
\hline & $\begin{array}{l}\text { Urban, } \\
n(\%)\end{array}$ & $\begin{array}{l}\text { Rural, } \\
n(\%)\end{array}$ & $p$-value & $\begin{array}{l}\text { Urban, } \\
n(\%)\end{array}$ & $\begin{array}{l}\text { Rural, } \\
n(\%)\end{array}$ & $p$-value \\
\hline Education & & & 0.000 & & & 0.000 \\
\hline None & $10(3.1)$ & $14(6.3)$ & & $11(1.5)$ & $20(3.0)$ & \\
\hline Primary & $73(22.7)$ & $108(48.6)$ & & $137(19.2)$ & $297(43.9)$ & \\
\hline Secondary & $201(62.4)$ & $93(41.9)$ & & $510(71.6)$ & $337(49.9)$ & \\
\hline Post-secondary & $38(11.8)$ & $7(3.2)$ & & $54(7.6)$ & $22(3.3)$ & \\
\hline Income group & & & 0.000 & & & 0.000 \\
\hline Lowest & $26(12.9)$ & $58(35.6)$ & & $82(16.7)$ & $206(34.9)$ & \\
\hline Middle & $74(36.8)$ & $77(47.2)$ & & $239(48.7)$ & $325(55.0)$ & \\
\hline Highest & $101(50.2)$ & $28(17.2)$ & & $170(34.6)$ & $60(10.2)$ & \\
\hline Employment & & & 0.052 & & & 0.004 \\
\hline Employed & $93(31.0)$ & $42(22.8)$ & & $166(25.9)$ & $102(18.9)$ & \\
\hline Unemployed & $207(69.0)$ & $142(77.2)$ & & $476(74.1)$ & $438(81.1)$ & \\
\hline Marital status & & & 0.012 & & & 0.000 \\
\hline Single & $133(41.4)$ & $67(30.6)$ & & $351(49.6)$ & $190(28.1)$ & \\
\hline Married/cohabiting & $146(45.5)$ & $125(57.1)$ & & $240(33.9)$ & $299(44.2)$ & \\
\hline Widow(er) & $14(4.4)$ & $15(6.8)$ & & $75(10.6)$ & $150(22.2)$ & \\
\hline Divorced/separated & $28(8.7)$ & $12(5.5)$ & & $41(5.8)$ & $37(5.5)$ & \\
\hline
\end{tabular}

users of alcohol. ${ }^{[20]}$ The higher prevalence of alcohol use in the urban population in our study could be explained by the fact that there were proportionally more males and single participants in this group compared with the rural group, and these two factors were found to be significantly associated with alcohol use.

We found statistically non-significant associations between level of education attained and most CVD risk factors (except for tobacco use). Education has been suggested as the single most useful SES variable that predicts CVD risk prevalence. Winkleby et al. ${ }^{[21]}$ reported that education had the most consistent association with CVD risk factors in the USA. Our findings suggest that this may not necessarily be the case, especially in LMICs, where many other factors play roles in disease development. The level of education of our study participants was not different from that of the general SA population. Overall, the number of people who had attained higher education was low, consistent with findings from the 2011 South African census ${ }^{[2]}$ that only $8.3 \%$ of black South Africans had attained postsecondary education as of 2011. In our study, educational attainment was found to 
correlate positively with employment (Spearman's rank correlation coefficient $=0.241 ; p<0.001)$. Differences in level of education attained may explain why monthly household income differed significantly between the urban and rural groups. However, level of education was not significantly associated with CVD risk prevalence. These lacks of association between education and CVD prevalence may suggest that while higher education may signify higher SES, employment status and income of the individual may be better predictors of CVD risk prevalence than education.

\section{Study limitations}

In spite of stringent efforts to minimise bias, there was a potential for recall and measurement bias in the primary study, arising from eliciting information regarding the CVD risks from participants. The current study is reliant on the data integrity of the primary study.

Diabetes diagnosis was based on self-reported history of the disease, with no biochemical results available at the time of writing. This may have led to under-reporting of diabetes prevalence among our study participants.

Neither physical activity nor dietary intake were included in the study owing to lack of data, and this may explain some of the associations, or lack of them.

In the primary study, proportionally more females than males were recruited. This could potentially influence results in instances when gender is known to be associated with the variable under review. To reduce the impact, we adjusted for gender in our multivariable analysis.

Furthermore, the primary study recruited participants from mostly isiXhosa-speaking areas of the Eastern Cape and Cape Town, so the study population cannot be said to be representative of all black South Africans. This may limit the generalisability of our findings.

During analysis, we found that almost all the participants in the study had an income that classified them as of lower SES as far as income was concerned. This is a potential source of bias and may restrict the generalisability of the finding to all SES levels, but the findings show that even within similar SES groups, we may be experiencing differences in CVD risk prevalence.

Despite these limitations, the findings of this study highlight the need for more enquiry into associations between SES and CVD risk factors in SA.

\section{Conclusions and recommendations}

This study supports the suggestion that the socioeconomic profile of adult South Africans differs significantly between rural and urban populations and showed that individual CVD risk factors were significantly more prevalent in the urban than in the rural location. Our demonstration that SES is significantly associated with CVD risk factors in this cohort of participants, and that gender, marital status, income and location are all predictors of this association, supports the inclusion of SES as a factor in programming for CVD risk control intervention. However, further studies are required to establish the mechanism through which marital status affects an individual's susceptibility to CVD risk, especially for widowed persons.
Acknowledgements. The authors would like to acknowledge all research assistants and participants in both study sites and the PURE Study investigators. This study was partly supported by funding from the Population Health Research Institute, Hamilton Health Sciences and McMaster University, Hamilton, Canada. EUI is supported in part by the National Research Foundation of South Africa (UID: 86003). The opinions, findings, conclusions and recommendations expressed are those of the authors and the funders accept no liability whatsoever in this regard.

1. World Health Organization. Global status report on non-communicable diseases 2014. 2015. http:// apps.who.int/iris/bitstream/10665/148114/1/9789241564854_eng.pdf?ua=1 (accessed 12 August 2015)

2. Amplavanar NT, Gurpreet K, Salmiah MS, Odhayakumar N. Prevalence of cardiovascular disease risk factors among attendees of the Batu 9, Cheras Health Centre, Selangor, Malaysia. Med J Malaysia 2010;65(3):173-179.

3. World Health Organization. Cardiovascular disease factsheet. 2011. http://www.who.int/mediacentre/ World Health Organization. Cardiovascular disease factsh.
factsheets/fss317/en/index.html (accessed 2 August 2011).

4. Van Zyl S, van der Merwe LJ, Walsh CM, van Rooyen FC, van Wyk HJ, Groenewald AJ. A risk-factor profile for chronic lifestyle diseases in three rural Free State towns. S Afr Fam Pract 2010;52(1):72-76. DOI:10.1080/20786204.2010.10873940

5. Mayosi BM, Flisher AJ, Lalloo UG, Sitas F, Tollman SM, Bradshaw D. The burden of noncommunicable diseases in South Africa. Lancet 2009;374(9693):934-947. DOI:10.1016/S01406736(09)61087-4

6. Steyn K, Fourie JM. The Heart and Stroke Foundation South Africa. Media Data Document. Cape Town: Department of Medicine, University of Cape Town, and Chronic Diseases of Lifestyle Unit, 2007.

7. Puoane T, Tsolekile L, Sanders D, Parker W. Chronic non-communicable ciseases. In: Barron P, RomaReardon J, eds. South African Health Review. 13th ed. Durban: Health Systems Trust, 2008. http:/ www.hst.org.za/uploads/files/chap5_08.pdf (accessed 15 June 2015).

8. Lynch JW, Kaplan GA, Cohen RD, Tuomilehto J, Salonen JT. Do cardiovascular risk factors explain the relation between socioeconomic status, risk of all-cause mortality, cardiovascular mortality, and acute
rental relation between socioeconomic status, risk of all-cause morta
myocardial infarction? Am J Epidemiol 1996;144(10):934-942.

myocardial infarction? Am J Epidemiol 1996;144(10):934-942.
9. Mathenge W, Foster A, Kuper H. Urbanization, ethnicity and cardiovascular risk in a population

Mathenge W, Foster A, Kuper H. Urbanization, ethnicity and cardiovascular risk in a population
in transition in Nakuru, Kenya: A population-based survey. BMC Public Health 2010;10:569. in transition in Nakuru, Keny
DOI:10.1186/1471-2458-10-569

10. Gupta R, Guptha S, Sharma KK, Gupta A, Deedwania P. Regional variations in cardiovascular risk factors in India: India heart watch. World J Cardiol 2012;4(4):112-120. DOI:10.4330/wjc v4.i4.112

11. Marmot M, Friel S, Bell R, Houweling TA, Taylor S, Commission on Social Determinants of Health. Closing the gap in a generation: Health equity through action on the social determinants of health Lancet 2008;372(9650):1661-1669. DOI:10.1016/S0140-6736(08)61690-6

2. World Bank. GINI index (World Bank estimate). Updated 2015. http://data.worldbank.org/indicator/ SI.POV.GINI (accessed 12 August 2015).

3. World Health Organization. Training for Mid-level Managers: The EPI Coverage Survey. Geneva: WHO Expanded Programme on Immunization, 1991.

14. Zhang Z, Hayward MD. Gender, the marital life course, and cardiovascular disease in late midlife. J Marriage Fam 2006;68(3):639-657. DOI:10.1159/000355576

15. Wilcox S, Evenson K, Aragaki A, Wassertheil-Smoller S, Mouton C, Loevinger B. The effects of Wilcox S, Evenson K, Aragaki A, Wassertheil-Smoller S, Mouton C, Loevinger B. The effects of
widowhood on physical and mental health, health behaviors, and health outcomes: The Women's widowhood on physical and mental health, health behaviors, and health outcomes: 'Th
Health Initiative. Health Psychol 2003;22(5):513-522. DOI:10.1037/0278-6133.22.5.513

16. Kruger HS, Venter CS, Vorster H. Physical inactivity as a risk factor for cardiovascular disease in communities undergoing rural to urban transition: The THUSA study. Cardiovasc J S Af 2003;14(1):16-23.

17. Steyn K, Fourie J, Temple N. Chronic Diseases of Lifestyle in South Africa: 1995-2005. Cape Town: South African Medical Research Council, 2006:33-47.

18. Gautier PA, Svarer M, Teulings CN. Sin city? Why is the divorce rate higher in urban areas? Scand J Econ 2009;111(3):439-456. DOI:10.1111/j.1467- 9442.2009.01571.x

19. Peer N, Lombard C, Steyn K, Levitt N. Differential associations of cardiovascular disease risk factors with relative wealth in urban-dwelling South Africans. J Public Health 2015. DOI:10.1093/pubmed/ fdv152

20. National Department of Health, Medical Research Council, OrcMacro. South Africa Demographic and Health Survey 2003. Pretoria: NDoH, 2007. https://dhsprogram.com/pubs/pdf/FR206/FR206.pdf (accessed 28 July 2016).

21. Winkleby M, Jatulis D, Frank E, Fortmann S. Socioeconomic status and health: How education, Winkleby M, Jatulis D, Frank E, Fortmann S. Socioeconomic status and health: How education,
income, and occupation contribute to risk factors for cardiovascular disease. Am J Public Health 1992;82(6):816-820. DOI:10.2105/AJPH.82.6.816

22. Statistics South Africa. Census 2011, Statistical Release (Revised) P0301.4. http://www.statssa.gov.za/ publications/P03014/P030142011.pdf (accessed 9 September 2013).

Accepted 21 June 2016 